\title{
ARTICLES
}

\section{Molecular Evolution and Intratumor Heterogeneity by Topographic Compartments in Muscle-Invasive Transitional Cell Carcinoma of the Urinary Bladder}

\author{
Salvador J. Diaz-Cano, Alfredo Blanes, Javier Rubio, Alfredo Matilla, and \\ Hubert J. Wolfe
}

Department of Pathology (SJD-C), St Bartholomew's and the Royal London School of Medicine and Dentistry, London, United Kingdom; Tufts University-New England Medical Center (SJD-C, HJW), Boston, Massachusetts; and the University Hospital of Málaga (AB, JR, AM), Málaga, Spain

\begin{abstract}
SUMMARY: Superficial transitional cell carcinomas (TCC) of the urinary bladder have been shown to be monoclonal. However, no combined study of clonality and tumor suppressor genes (TSG) is available to date for muscle-invasive TCC. Forty-four muscle-invasive TCC of the urinary bladder selected from women were included in this study. Tumor cells located above and below the muscularis mucosa zone were systematically microdissected and used for DNA extraction. Hha-I digested and undigested samples were used to study the methylation pattern of androgen receptor alleles and undigested samples were used for microsatellite analysis of TSG (TP53, RB1, WT1, and NF1). Both loss of heterozygosity (LOH) and single nucleotide polymorphism (SNP) analyses were performed using optimized denaturing gradient gel electrophoresis. The expression of p53, $\mathrm{pRB}$, and $\mathrm{p} 21^{\mathrm{WAF} 1}$ was assessed by immunohistochemistry. Appropriate controls were run in every case. All except two TCC showed a monoclonal pattern with the same allele inactivated in both compartments. Microsatellite analysis of TSG revealed the same LOH/SNP pattern in both tumor compartments in 30 cases (involving more than 1 TSG locus in 8) and genetic heterogeneity in 14 cases. From the latter group, 9 cases expressed more genetic changes in the deep compartment (involving TP53 gene in all cases, WT1 gene in 2, and NF1 in 1), whereas in 4 cases the superficial compartment showed more genetic changes (three involving NF1 and one involving both RB and TP53). No statistical difference in the immunoexpression was detected, although it tended to be higher in the superficial compartment than in the deep compartment. These concordant data in polymorphic DNA regions indicate that bladder-muscle-invasive TCC are monoclonal proliferations with homogeneous tumor cell selection. Heterogeneous tumor cell selection by topography defined two different genetic compartments: superficial, NF1-defective, and deep, TP53-defective. No differences in the immunohistochemical expression were observed, precluding a more extensive clinical application. (Lab Invest 2000, 80:279-289).
\end{abstract}

\begin{abstract}
S uperficial cancer of the urinary bladder often $\int$ presents as multiple tumors, appearing at different times and at different sites in the bladder. This observation has been attributed to a "field defect" in the bladder that allows the independent transformation of epithelial cells at a number of sites. Previous studies have shown the same $X$ chromosome inactivated in all tumors from a single patient, whereas normal bladder mucosa cells had random patterns of inactivation. Moreover, each tumor that could be evaluated from a given patient had lost the same allele on
\end{abstract}

Received July 20, 1999.

Presented in part as abstract at the USCAP Meetings in Boston, Massachusetts, 1998 and San Francisco, California, 1999.

Address reprint requests to: Dr. S. J. Diaz-Cano, Department of Histopathology and Morbid Anatomy, The Royal London Hospital, Whitechapel, London E1 1BB, United Kingdom. Fax: 44171377 7030; E-mail: s.j.diaz-cano@mds.qmw.ac.uk chromosome 9q, but with heterogeneous losses of chromosomes $17 p$ and $18 q$ alleles (Sidransky et al, 1992).

Point mutations, or single nucleotide polymorphism if located in introns, within all cells imply a common progenitor contributing that mutation (Knudson, 1995; Nowell, 1976), and have been found associated with loss of heterozygosity $(\mathrm{LOH})$ of certain loci (Sternlicht et al, 1994). Its demonstration applies only to those cases carrying that marker and fails to identify clonal proliferations occurring before the creation of a specific genetic lesion (Diaz-Cano et al, in press; Sternlicht et al, 1994). Nevertheless, certain genetic markers can be used to test clonal expansions within a tumor cell sample (Diaz-Cano, 1998; Diaz-Cano et al, in press). The $\mathrm{LOH}$ of a given genetic marker should be linked to loss of tumor suppressor genes (TSG) by DNA deletions, one of the key components of Knudson's hypothesis (Knudson, 1995). The TP53/RB mutation status of recurrent bladder cancers has com- 
pletely matched their corresponding primary bladder cancer, suggesting a monoclonal origin of recurrent superficial bladder cancer (Chern et al, 1996).

Histologic heterogeneity is well documented in transitional cell carcinoma (TCC), even for xenograft tumors that have been reported to express transitional, squamous, and glandular elements in different clones. The DNA content and lectin binding profiles of the clones also reflects the heterogeneity of the line (Brown et al, 1990). Cytogenetic heterogeneity has also been demonstrated by comparative genomic hybridization (Voorter et al, 1995) and, in radiationinduced tumors, the presence of cytogenetically abnormal and unrelated clones has been assumed the result of heterogeneity of the tumor cell population (Fadl-Elmula et al, 1998). The analysis of marker chromosomes in tumors with two or more cultures has shown, besides a primary cytogenetic change, additional clonal abnormalities illustrating intratumoral heterogeneity (Nordenson et al, 1988). All these studies on tumor heterogeneity do not take into consideration the tumor cell topography in the urinary bladder wall.

The staging system in urinary bladder tumors has been improved after recognizing the relevance of the muscularis mucosa (Ro et al, 1987). The data show that the extent of lamina propria invasion is a clinically relevant prognostic factor for progression of pT1 TCC of the bladder (Smits et al, 1998; Younes et al, 1990). Tumors extending beyond the muscularis mucosa behave in a way similar to muscle-invasive TCC, especially if they are high-grade, reveal associated carcinoma in situ, or express nuclear TP53 (Hermann et al, 1998; Smits et al, 1998; Younes et al, 1990).

However, no combined study on the methylation pattern of androgen receptor alleles and microsatellite (MS) pattern of tumor suppressor genes (TSG) is available to date for muscle-invasive TCC. Likewise, there is no reference about the differences in the molecular profile of tumor cells located above and below the muscularis mucosa. The main aim of this study is to examine the molecular evolution and tumor heterogeneity by topographic compartments in a series of 44 muscle-invasive TCC, considering that tumor cell depth in the bladder wall would express the potential of cellular progression in TCC.

\section{Results}

Five cases were considered non-informative and were excluded from the clonality analysis because of the unbalanced methylation pattern of the undigested control samples (four cases) or MS instability involving the androgen receptor locus (one case). The remaining 39 cases revealed 37 TCC with a monoclonal pattern and the same $X$ chromosome inactivated in samples from a single patient and 2 TCC with a polyclonal pattern (Fig. 1).

The MS analysis of TSG revealed TP53 alterations in 29 of 43 informative cases $(67.4 \%$, screening two introns), RB abnormalities in 17 of 33 informative cases $(51.5 \%)$, WT1 genes lesions in 21 of 38 informative cases (55.3\%), and NF1 alterations in 19 of 30 informative cases (63.3\%). Fourteen TCC (31.8\%) revealed no genetic abnormalities in the TSG introns evaluated and included 3 non-informative cases, 1 case with MS instability, and 2 polyclonal cases in the test of $X$ chromosome inactivation. Eight additional TCC (18.2\%) revealed MS alterations involving the same locus in both tumor compartments: TP53 locus in 4 cases $(9.1 \%)$, WT1 locus in 3 cases $(6.8 \%)$, and RB1 locus in 1 case (2.3\%). Case TCC 7 showed TP53 $\mathrm{LOH}$ in the superficial compartment and WT1 LOH in the deep compartment; 3 TCC revealed only one TSG locus in one tumor compartment, either superficial (TP53, 1 case) or deep (TP53, 2 cases). The remaining TCC had two TSG loci altered in 13 cases $(29.5 \%, 7$ with superficial-deep concordance), three TSG loci in 4 cases $(9.1 \%, 1$ with superficial-deep concordance), and four TSG loci in 1 case $(2.3 \%)$.

Concordant MS patterns of TSG in both tumor compartments were observed in 30 muscle-invasive TCC (68.2\%) and topographically related genetic heterogeneity ( $\mathrm{LOH}$ and/or SNP) in 14 cases $(31.8 \%)$ (Table 1). In the latter group, 9 TCC (20.5\%) expressed more genetic changes in the deep compartment (TP53 gene in all cases, WT1 gene in 2, and NF1 in 1), and 4 cases $(9.1 \%)$ at the superficial compartment (3 involving NF1 and 1 involving both RB and TP53 genes) (Fig. 2, Table 1). One case (TCC 7) showed a discordant MS pattern of TSG, involving TP53 locus in the superficial compartment and WT1 locus in the deep compartment. The group of muscle-invasive TCC with concordant MS patterns of TSG showed a subset of tumors with demonstrable genetic alterations in at least one TSG locus (16 cases, 36.4\%) and another subset with no demonstrable alteration in TSG loci (14 cases, $31.8 \%)$.

A heterogeneous immunohistochemical expression of cell cycle regulators was observed with high variability of expression from field to field (high standard deviation). The antibodies used in this study detect the normal pRB1 and p21 WAF1 proteins, and both normal and abnormal p53 protein (clone DO1), but they were not able to differentiate groups of muscle-invasive TCC or topographic compartments. In any case, the protein expression tended to be higher in the superficial compartment than in the deep compartment (Figs. 3 and 4, Table 2). No statistically significant differences in the immunohistochemical expression of markers were detected by topography or tumor group.

\section{Discussion}

The concordant MS pattern of TSG and the inactivation of the same $X$ chromosome in both superficial and deep compartments of muscle-invasive TCC support a monoclonal origin and a homogeneous selection of tumor cell throughout the neoplasm. In approximately $70 \%$ of muscle-invasive TCC in this series, each patient had inactivation of the same $X$ chromosome and concordant MS pattern of TSG in both tumor compartments; in all these cases, normal bladder mucosa cells had random $X$-inactivation patterns and retained the constitutional heterozygosity. On the 

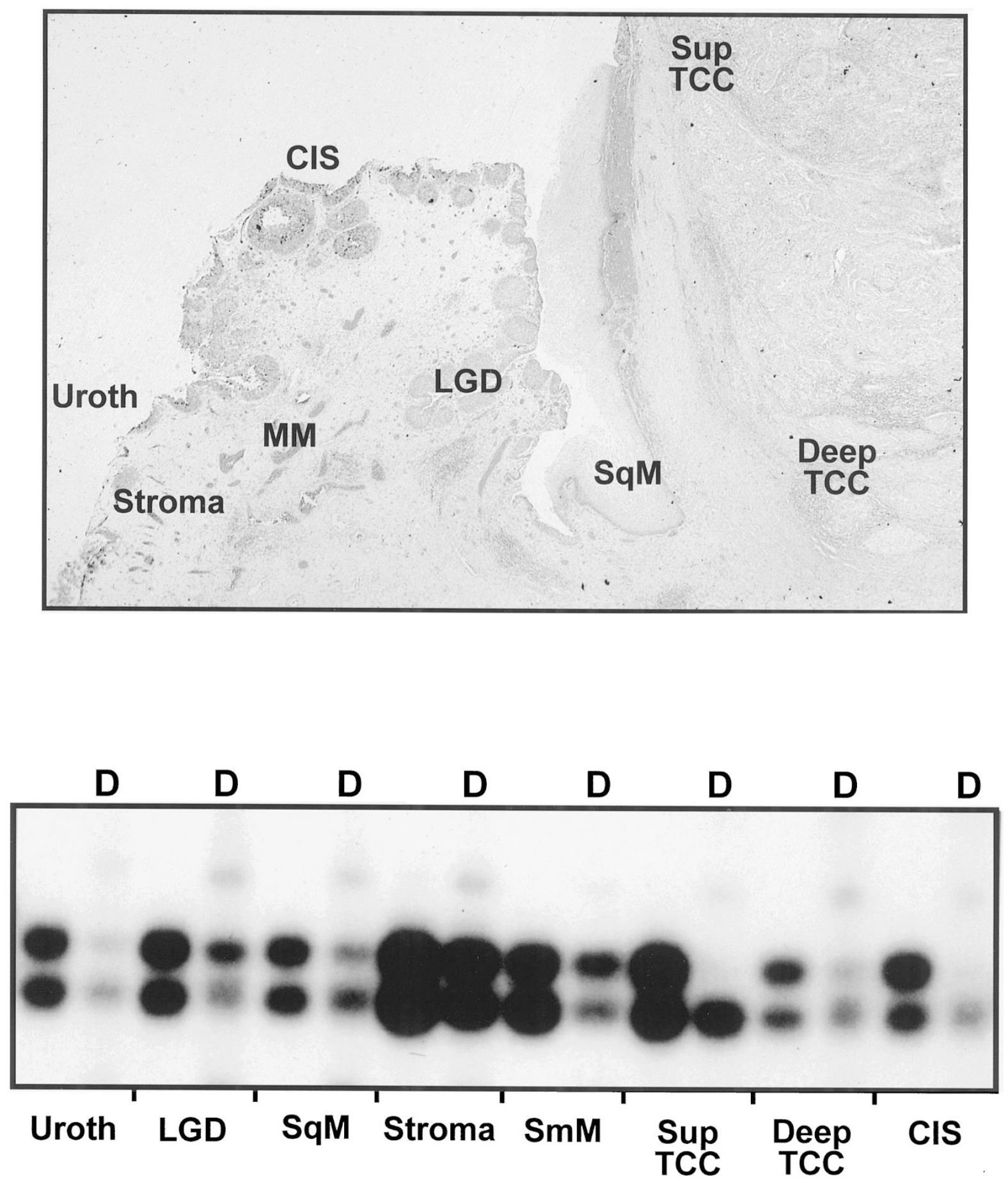

Figure 1.

Example of tumor cell and control sampling in muscle-invasive transitional cell carcinoma (TCC) of the urinary bladder (top panel) and clonality results (bottom panel). Note the unbalanced methylation pattern of androgen receptor alleles in the superficial tumor compartment (Sup TCC) and carcinoma in situ (CIS). The balanced pattern in the deep compartment (Deep TCC) was related to inflammatory cell contamination. The intraurothelial lesions are not part of this article. Uroth, histologically normal urothelium; LGD, low-grade dysplasia; SqM, squamous metaplasia; SmM, smooth muscle.

other hand, tumor cell heterogeneity by topographic compartments was demonstrated in 14 of 44 muscleinvasive TCC (31.8\%). Three main groups of molecular evolution could be drawn in muscle-invasive TCC: two in the first genetically homogeneous group and one for the heterogeneous group.
We found coexistent genetic abnormalities involving two or more TSG loci in the first group of muscleinvasive TCC (16 of 44 cases, 36.4\%). The background level of $\mathrm{LOH}$ in normal tissues has been reported between $4 \%$ and $20 \%$, regardless of the detection system used (Chen et al, 1992; Deng et al, 
Table 1. Muscle-Invasive Transitional Cell Carcinoma of the Urinary Bladder with Discordant Genetic Abnormalities in the Superficial and Deep Compartments

\begin{tabular}{|c|c|c|c|c|c|c|}
\hline Case/Sample & $\begin{array}{l}\text { Methylation of } \\
\text { AR Alleles* }\end{array}$ & TP53-1‡ & TP53-2‡ & RB1 $\ddagger$ & WT1‡ & NF1‡ \\
\hline TCC 1-Sup. & Unbalanced & LOH-S & $\mathrm{NI}$ & $\mathrm{ROH}$ & LOH-S & $\mathrm{LOH}-\mathrm{L}$ \\
\hline TCC 1-Deep & Unbalanced & SNP-SL & $\mathrm{NI}$ & $\mathrm{ROH}$ & LOH-S & $\mathrm{ROH}$ \\
\hline TCC 7-Sup. & Unbalanced & $\mathrm{LOH}-\mathrm{L}$ & $\mathrm{ROH}$ & $\mathrm{ROH}$ & $\mathrm{ROH}$ & $\mathrm{ROH}$ \\
\hline TCC 7-Deep & Unbalanced & $\mathrm{ROH}$ & $\mathrm{ROH}$ & $\mathrm{ROH}$ & $\mathrm{LOH}-\mathrm{L}$ & $\mathrm{ROH}$ \\
\hline TCC 10-Sup. & Unbalanced & SNP-S & $\mathrm{ROH}$ & LOH-S & $\mathrm{ROH}$ & SNP-S \\
\hline TCC 10-Deep & Unbalanced & SNP-S & $\mathrm{ROH}$ & $\mathrm{ROH}$ & $\mathrm{ROH}$ & $\mathrm{ROH}$ \\
\hline TCC 13-Sup. & Unbalanced & $\mathrm{LOH}-\mathrm{L}$ & $\mathrm{ROH}$ & LOH-S & $\mathrm{LOH}-\mathrm{L}$ & $\mathrm{LOH}-\mathrm{L}$ \\
\hline TCC 13-Deep & Unbalanced & $\mathrm{LOH}-\mathrm{L}$ & $\mathrm{ROH}$ & LOH-S & SNP-SL & $\mathrm{ROH}$ \\
\hline TCC 16-Sup. & Unbalanced & $\mathrm{ROH}$ & LOH-L & $\mathrm{ROH}$ & $\mathrm{ROH}$ & $\mathrm{ROH}$ \\
\hline TCC 16-Deep & Unbalanced & $\mathrm{ROH}$ & LOH-L & $\mathrm{ROH}$ & SNP & $\mathrm{ROH}$ \\
\hline TCC 21-Sup. & Unbalanced & $\mathrm{ROH}$ & $\mathrm{NI}$ & $\mathrm{ROH}$ & SNP-SL & $\mathrm{NI}$ \\
\hline TCC 21-Deep & Unbalanced & $\mathrm{LOH}-\mathrm{L}$ & $\mathrm{NI}$ & $\mathrm{ROH}$ & SNP-SL & $\mathrm{NI}$ \\
\hline TCC 23-Sup. & MSI & $\mathrm{ROH}$ & $\mathrm{ROH}$ & $\mathrm{NI}$ & $\mathrm{ROH}$ & $\mathrm{ROH}$ \\
\hline TCC 23-Deep & MSI & $\mathrm{ROH}$ & $\mathrm{LOH}-\mathrm{L}$ & $\mathrm{NI}$ & LOH-L & LOH-S \\
\hline TCC 26-Sup. & Unbalanced & $\mathrm{ROH}$ & $\mathrm{ROH}$ & - & $\mathrm{ROH}$ & $\mathrm{ROH}$ \\
\hline TCC 26-Deep & Unbalanced & LOH-S & LOH-S & - & $\mathrm{ROH}$ & $\mathrm{ROH}$ \\
\hline TCC 30-Sup. & $\mathrm{NI}$ & $\mathrm{LOH}-\mathrm{L}$ & $\mathrm{NI}$ & $\mathrm{ROH}$ & $\mathrm{ROH}$ & - \\
\hline TCC 30-Deep & $\mathrm{NI}$ & $\mathrm{ROH}$ & $\mathrm{NI}$ & $\mathrm{ROH}$ & $\mathrm{ROH}$ & - \\
\hline TCC 31-Sup. & Balanced & $\mathrm{ROH} / \mathrm{SNP}-\mathrm{SL}$ & $\mathrm{ROH}$ & $\mathrm{NI}$ & $\mathrm{ROH}$ & $\mathrm{NI}$ \\
\hline TCC 31-Deep & Unbalanced & LOH/SNP-S & $\mathrm{ROH}$ & $\mathrm{NI}$ & $\mathrm{LOH}-\mathrm{L}$ & $\mathrm{NI}$ \\
\hline TCC 35-Sup. & Unbalanced & $\mathrm{ROH}$ & $\mathrm{ROH}$ & $\mathrm{NI}$ & $\mathrm{ROH}$ & $\mathrm{ROH}$ \\
\hline TCC 35-Deep & Unbalanced & LOH-S & $\mathrm{ROH}$ & $\mathrm{NI}$ & $\mathrm{ROH}$ & $\mathrm{ROH}$ \\
\hline TCC 37-Sup. & Unbalanced & $\mathrm{ROH}$ & $\mathrm{ROH}$ & LOH-S & $\mathrm{ROH}$ & $\mathrm{ROH}$ \\
\hline TCC 37-Deep & Balanced & LOH-S & $\mathrm{ROH}$ & LOH-S & $\mathrm{ROH}$ & $\mathrm{ROH}$ \\
\hline TCC 43-Sup. & Unbalanced & $\mathrm{ROH}$ & $\mathrm{ROH}$ & $\mathrm{ROH}$ & $\mathrm{ROH}$ & $\mathrm{ROH}$ \\
\hline TCC 43-Deep & Unbalanced & $\mathrm{ROH}$ & $\mathrm{LOH}-\mathrm{L}$ & $\mathrm{ROH}$ & $\mathrm{ROH}$ & $\mathrm{ROH}$ \\
\hline TCC 44-Sup. & Unbalanced & $\mathrm{ROH}$ & $\mathrm{ROH}$ & $\mathrm{ROH}$ & $\mathrm{ROH}$ & $\mathrm{ROH}$ \\
\hline TCC 44-Deep & Unbalanced & $\mathrm{ROH}$ & $\mathrm{LOH}-\mathrm{S}$ & $\mathrm{ROH}$ & $\mathrm{ROH}$ & $\mathrm{ROH}$ \\
\hline
\end{tabular}

${ }^{*}$ AR, androgen receptor; NI, non informative; MSI, microsatellite instability.

$\ddagger$ Tumor suppressor genes were evaluated for the presence of loss of heterozygosity $(\mathrm{LOH})$, retention of heterozygosity $(\mathrm{ROH})$, and single nucleotide polymorphism (SNP) in the small (S) and large (L) alleles. NI, noninformative.

1996; Sager, 1989; Wolman and Heppner, 1992). Similar LOH frequency must be assumed as background in the evaluation of tumor tissues (Sager, 1989). Considering the worst-case scenario of all genetic lesions being equally important and frequent (Diaz-Cano and Wolfe, 1997), the probability of randomly finding coexisting genetic alterations in normal tissues would be $0.2^{2}=4.0 \times 10^{-2}$ for two genetic loci, $0.2^{3}=8.0 \times 10^{-3}$ for three genetic loci, and so on. Applying this principle to two separately microdissected samples (superficial and deep) from any given single tumor, the probability of having the same locus involved in both samples would be $\left(0.2^{1}\right)^{2}=4.0 \times$ $10^{-2}$ for one genetic locus, $\left(0.2^{2}\right)^{2}=1.6 \times 10^{-3}$ for two genetic loci, or $\left(0.2^{3}\right)^{2}=6.4 \times 10^{-5}$ for three genetic loci. Under these circumstances, the probability of randomly finding concordant genetic abnormalities in both superficial and deep compartments in 16 patients ( 8 involving one TSG locus, 7 involving two TSG loci, and 1 involving three TSG loci) would be $\left[\left(0.2^{1}\right)^{2}\right]^{8}\left[\left(0.2^{2}\right)^{2}\right]^{7}\left[\left(0.2^{3}\right)^{2}\right]^{1}=1.13 \times 10^{-35}$. That result strongly supports the monoclonal origin and a homogeneous selection of tumor cells throughout the neoplasm. On the other hand, it also suggests that this subset of muscle-invasive TCC can arise from the uncontrolled spread of a single transformed cell and evolve through a multistep tumorigenesis involving those "common" TSG.

In general, the accumulation of genetic lesions in TSG supports a monoclonal origin of tumors (DiazCano, 1998). Similar findings have been reported in coexistent superficial bladder TCC, but comparing different tumors instead of tumor compartments (Sidransky et al, 1992). Muscle-invasive TCC represent advanced neoplasms, and an accumulation of genetic abnormalities can be expected when compared with reference TCC, if we consider that accumulation of genetic alterations is an expression of molecular progression. It would help to explain the relatively high incidence of genetic abnormalities found in RB1 and WT1 loci. Horowitz et al (1990) found inactivated $\mathrm{pRB}$ in one-third of randomly selected bladder cancers, compared with our $51.5 \%$ incidence of RB1 abnormalities. Kageyama et al (1995) did not find WT1 mutations in any of 11 randomly selected bladder cancers using polymerase chain reactionsingle strand conformation polymorphism analysis and restriction fragment length polymorphism analysis 

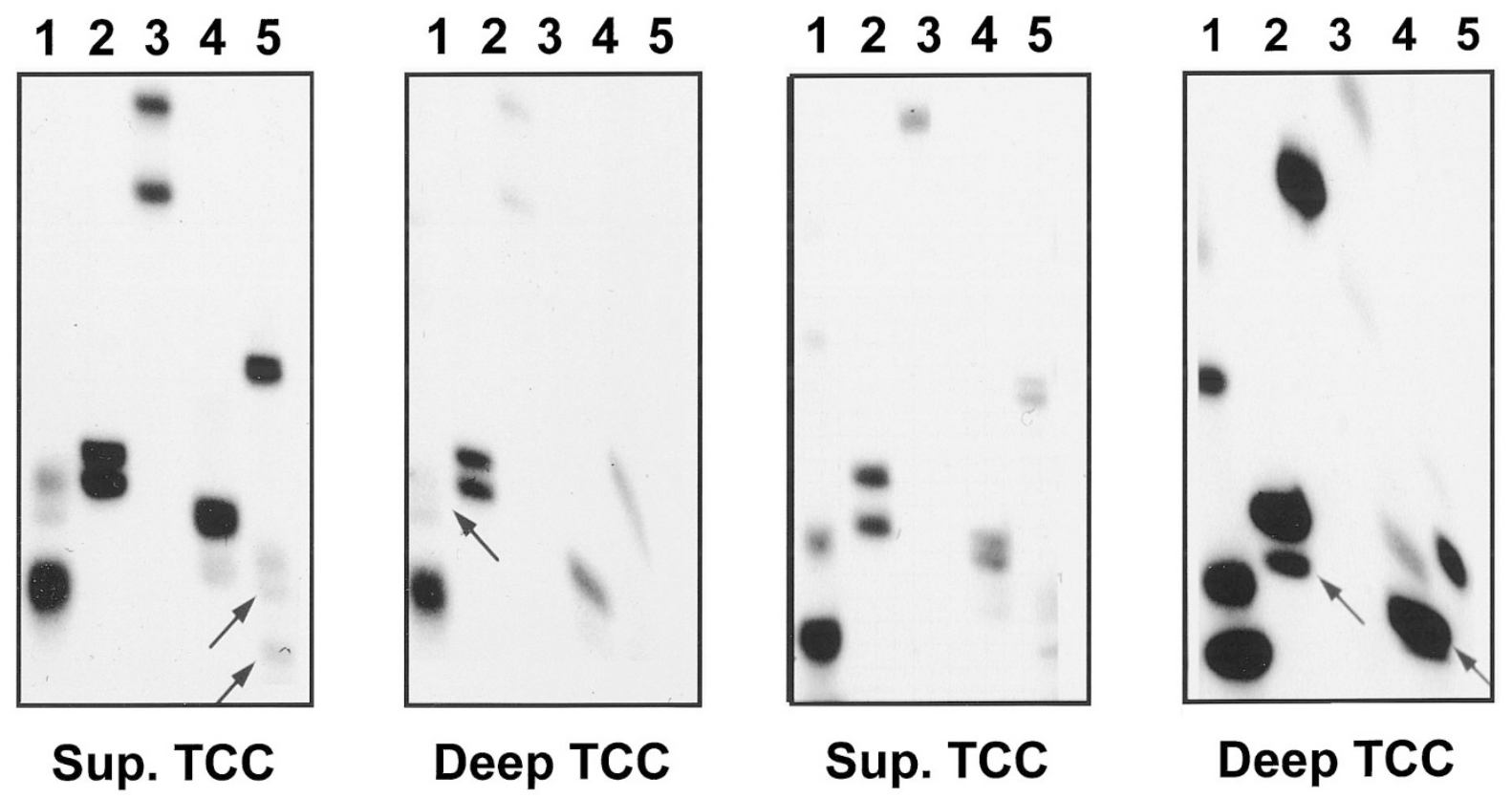

\section{Figure 2.}

Comparison of allele patterns of tumor suppressor genes in the superficial (Sup. TCC) and deep (Deep TCC) compartments from two examples of muscle-invasive transitional cell carcinoma (TCC) of the urinary bladder. Deep compartments show more genetic abnormalities in tumor suppressor gene introns than superficial compartments involving especially TP53 (arrows in lane 1 of panel a and lane 2 of panel b point to allelic imbalance as demonstrated in the densitometric analysis). Panel a also shows single nucleotide polymorphism of NF1 in the superficial compartment, and panel b shows allelic imbalance of WT1 in the deep compartment. Lanes 1, TP53(1); 2, TP53(2); 3, RB1; 4, WT1; 5, NF1.

of the WT1 locus. In addition, they only performed exon analysis for point mutation and no $\mathrm{LOH}$ analysis or intron analysis was carried out.

The second group of muscle-invasive TCC also showed homogeneous cell selection by tumor compartment but no demonstrable genetic alteration in the TSG introns evaluated. Fourteen muscle-invasive TCC (31.8\%) did not reveal intron deletions or single nucleotide polymorphisms, suggesting a reduced incidence of genetic damage in those TSG loci. Some alternative explanations could be offered for those cases.

(A) Genetic alterations below the detection threshold could explain that result. We previously optimized the denaturing gradient gel electrophoresis protocol with appropriate controls, including positive, negative, and sensitivity (not shown); the progressive dilution of a known positive case in a background of germline DNA gave us a sensitivity threshold of $1 \%$ for positive detection. We systematically microdissected at least 100 cells from each tumor compartment. With a sensitivity threshold of $1 \%$, the technique would miss the positive results from the DNA equivalent of less than one cell in the sampling, which is probably clinically irrelevant. Potential reasons could be normal tissue contamination, which could be excluded by repeated microdissection with the same results.

(B) Genetic alterations in those TSG could be present outside of the screened introns. Even in that situation, a statistical approach would prove that it is unlikely to find that association randomly, confirming that this group is a true subset of muscle-invasive TCC. If we consider 0.8 to be the probability of finding no-LOH for a given marker $[\mathrm{p}(\mathrm{no}-\mathrm{LOH})=1-$ $\mathrm{p}(\mathrm{LOH})=1-0.2=0.8]$, then $\mathrm{p}(\mathrm{no}-\mathrm{LOH})$ for five markers from a single sample would be $0.8^{5}=0.33$. We microdissected from the superficial and deep areas of TCC; the p(no-LOH) for two samples would be $\left(0.8^{5}\right)^{2}=0.11$. The probability that such consistent results would be randomly found in 14 patients would be $\left[\left(0.8^{5}\right)^{2}\right]^{14}=2.71 \times 10^{-14}$. Supporting that hypothesis, preliminary results of the histopathologic evaluation of those tumors revealed a particular growth pattern in the deep compartment, predominantly single-file infiltration (not shown). We can speculate that the malignant transformation of those tumors should target genes involved in cellular adhesion, thus disturbing the growth pattern. This particular aspect would need additional investigation.

The last subset of muscle-invasive TCC showed intratumor heterogeneity in the selection of tumor cells by topographic compartments (14 cases, 31.8\%). After malignant transformation, tumor cells can grow independently with variable subsequent genetic alterations in each tumor compartment, explaining the heterogeneity. This group of tumors would also result from the accumulation of genetic damage like the first subgroup. The number of cases is not large, but two processes of tumor cell selection seem to involve different TSG and be responsible for that topographic 

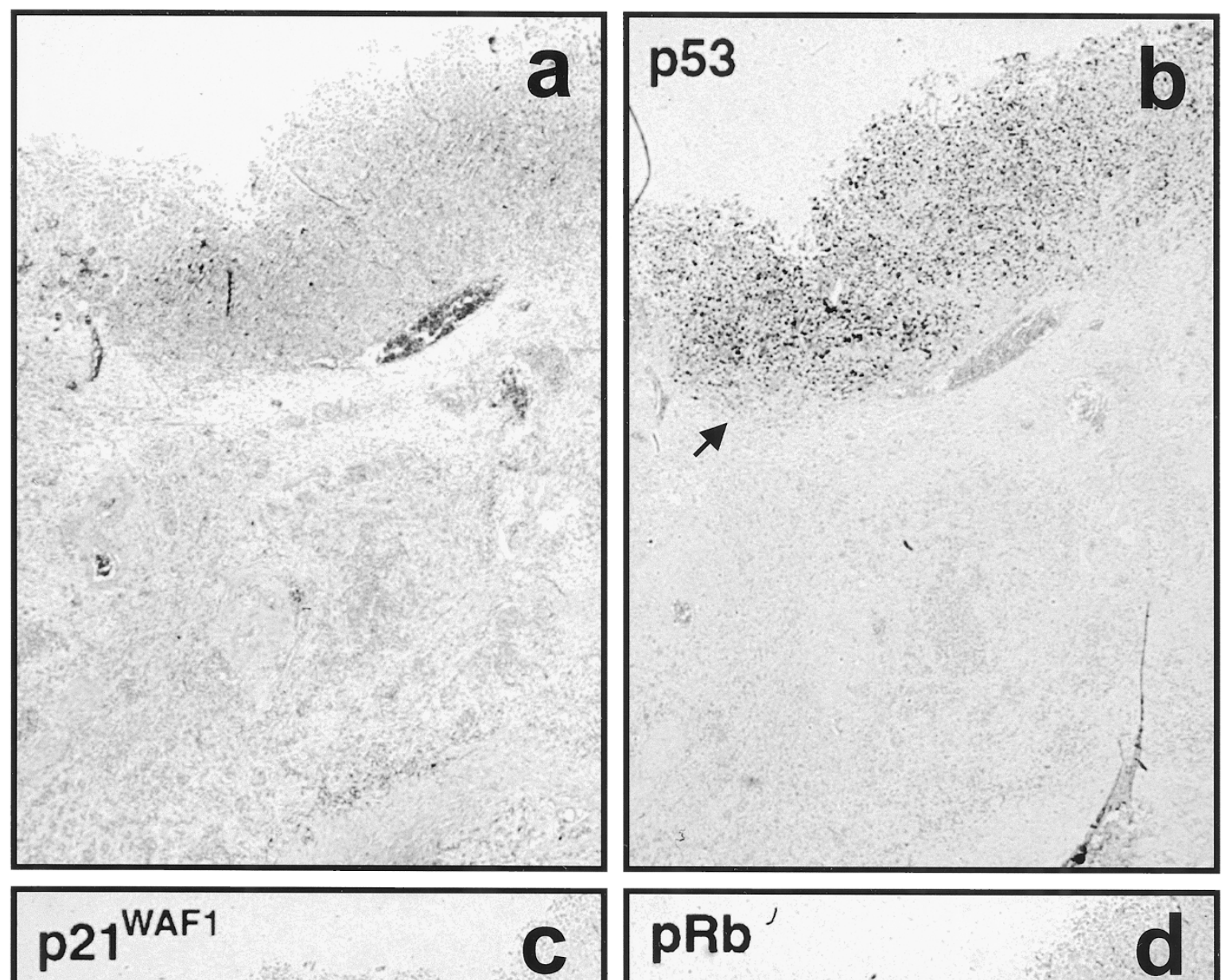

Figure 3.

The immunohistochemical expression of p53, p21WAF1, and pRb was more extensive in the superficial compartment of muscle-invasive transitional cell carcinoma (arrows) than in the deep compartment. Panel a shows the same field stained with hematoxylin-eosin. 


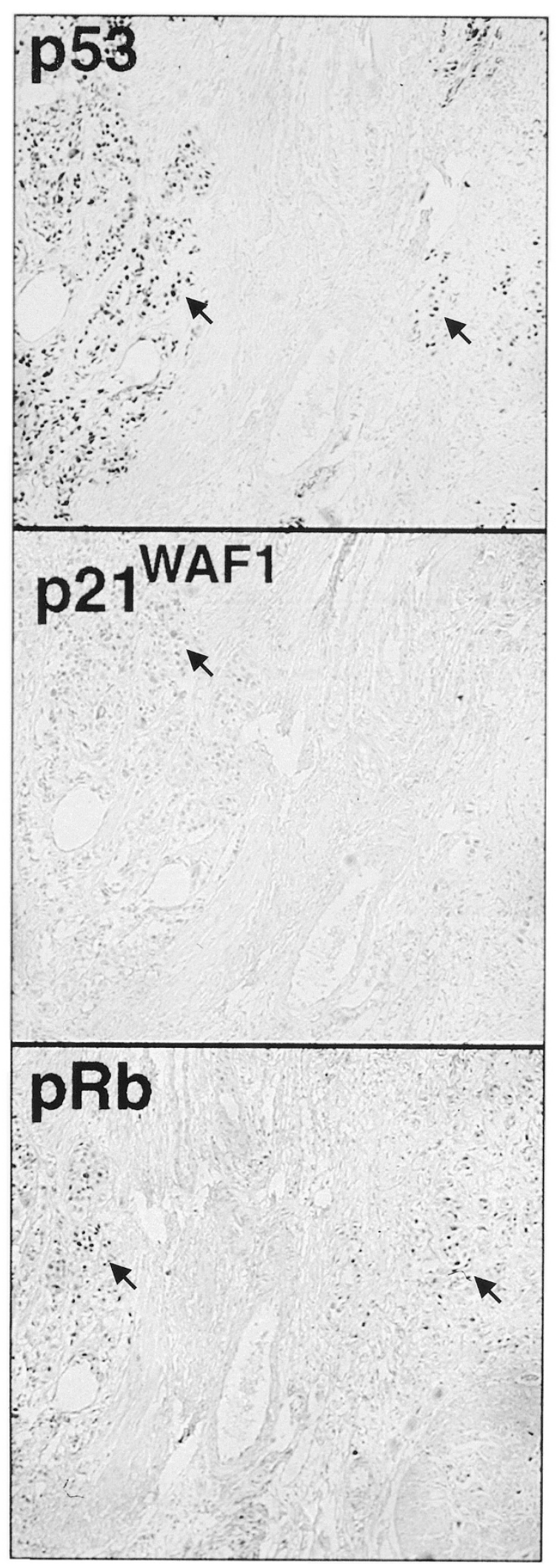

Figure 4.

Immunohistochemical expression of p53, p21WAF1, and pRb in the deep compartment of muscle-invasive transitional cell carcinoma (arrows) from the case shown in Figure 3.
Table 2. Immunohistochemical Expression of p53, p21 ${ }^{\text {WAF1 }}$, and pRB1 by Topographic Compartments in Muscle-Invasive Transitional Cell Carcinoma of the Urinary Bladder

\begin{tabular}{lcc}
\hline & $\begin{array}{c}\text { Superficial compartment } \\
(\text { Av. } \pm \text { sD) })^{*}\end{array}$ & $\begin{array}{c}\text { Deep compartment } \\
(\text { Av. } \pm \text { SD })^{*}\end{array}$ \\
\hline p53 (\%) & $60.36 \pm 27.32$ & $52.49 \pm 26.94$ \\
p21 $\%$ AF1 $(\%)$ & $42.13 \pm 21.38$ & $35.95 \pm 15.56$ \\
pRB $(\%)$ & $52.25 \pm 19.95$ & $47.59 \pm 14.76$ \\
\hline
\end{tabular}

${ }^{*} \mathrm{Av}$, average; SD, standard deviation.

heterogeneity. The differential TSG most frequently altered was NF1 in the superficial compartment $(75 \%$ of cases), and TP53 in the deep compartment (all cases). The NF1 gene has been rarely implicated in bladder carcinogenesis, and no mutations have been observed in a series of 31 bladder cancers studied by Uchida et al (1995). However, the presence of NF1 gene abnormalities in $63.3 \%$ of muscle-invasive TCC in our series (19 of 30 informative cases) supports an important role for NF1 in this malignant pathway, especially in the superficial tumor compartment. NF1 gene product has an effect on ras inhibition, protein expressed with the highest levels in immature and proliferating cells (Furth et al, 1987). The absence of the NF1 inhibitory effect will favor increased cell proliferation, as found in the superficial tumor compartments of muscle-invasive TCC (Blanes et al, 1999). Likewise, Aaltonen et al (1999) have reported a decreased NF1 mRNA and protein levels in high-grade TCC, suggesting that alterations in NF1 gene expression may be involved in bladder carcinogenesis. On the other hand, we found TP53 abnormalities in 29 of 43 informative cases (67.4\%), after screening two introns. This proportion is similar to that originally reported by Sidransky et al (1991) who found TP53 alterations in 11 of 18 invasive TCC, associated with $17 p$ allelic deletions in all but 1 case, and leaving cells with only mutant forms of the p53 gene product. TP53 abnormalities tended to concentrate in the deep tumor compartment, suggesting it can represent the consequence of tumor cell selection. Similarly, the loss of chromosome 17p has been reported as a late event in tumor progression in superficial TCC (Sidransky et al, 1992).

In conclusion, three main groups of molecular evolution could be drawn in muscle-invasive TCC of the urinary bladder. The first two groups result in homogeneous cell selection in the tumor progression, expressed by concordant patterns of TSG microsatellite and inactivation of the same $X$ chromosome, but with different molecular pathways. In one group, the progression takes place through the accumulation of genetic lesions in TSG, and in the other group, probably through a different genetic target. The third group is characterized by topographic tumor heterogeneity and by the accumulation of genetic lesions in TSG. Two genetically different topographic compartments were then apparent: superficial, NF1-defective, and deep, TP53-defective. 


\section{Materials and Methods}

\section{Case Selection and Sampling}

We reviewed all muscle-invasive TCC of the urinary bladder (pT2 and pT3) diagnosed in women during a time period of 5 years from three reference hospitals. Forty-four cases had properly preserved archival material available for further analyses, including both tumor and control tissues (histologically normal urothelium, lamina propria, and smooth muscle from the same patient).

All surgical specimens were completely embedded for histopathologic diagnosis. Two topographic compartments were analyzed in each TCC regarding their relationship with the muscularis mucosa (MM), revealed by its ectatic vascular plexus (Fig. 1) (Ro et al, 1987). Tumor cells above MM were labeled superficial, whereas those neoplastic cells located below the MM were considered deep. The same areas in consecutive sections were used in each study and their cellular composition was confirmed in adjacent hematoxylineosin stained sections.

\section{Clonality Analysis}

DNA was extracted from the selected areas using two 20- $\mu \mathrm{m}$ unstained paraffin sections and a modified phenol-chloroform protocol (Diaz-Cano and Brady, 1997). Appropriate controls were included for each test (histologically normal urothelium, stroma from the lamina propria, and smooth muscle). All samples were divided for restriction endonuclease digestion with Hha-I (New England Biolabs, Beverly, Massachusetts). Half of each sample underwent enzymatic digestion ( 0.8 unit/ $\mu \mathrm{l}$ ); the remaining half was kept as undigested control. Both samples were equally processed, but excluding Hha-I in the undigested one (Allen et al, 1992; Diaz-Cano et al, in press; Mutter and Boynton, 1995a; Mutter et al, 1995). A mimicker (0.3 $\mu \mathrm{g}$ of double stranded and Xhol-linearized $\phi$ X174-RII phage; Gibco-BRL, Gaithersburg, Maryland) was included in each reaction for digestion testing. Complete digestion was checked by gel electrophoresis; incompletely digested samples were repurified and redigested with higher Hha-I concentration.

Hha-I was then inactivated by phenol-chloroform extraction (Diaz-Cano and Brady, 1997). DNA was precipitated with ice-cold absolute ethanol in the presence of $0.3 \mathrm{M}$ sodium acetate, $\mathrm{pH} 5.2$, and resuspended in $10 \mu \mathrm{l}$ of PCR buffer (10 mM Tris- $\mathrm{HCl} \mathrm{pH} \mathrm{8.4,}$ $50 \mathrm{~mm} \mathrm{KCl}, 1.5 \mathrm{~mm} \mathrm{MgCl}_{2}$, and $100 \mu \mathrm{g} / \mathrm{ml} \mathrm{BSA}$ ). The hypervariable CAG repeat in the first exon of the human androgen receptor gene (HUMARA) was then amplified using both digested and undigested DNA templates (Mutter and Boynton, 1995a; Mutter et al, 1995). The tests were run in a Perkin-Elmer thermal cycler model 480 (Perkin-Elmer, Norwalk, Connecticut), according to the conditions shown in Table 3.

The whole PCR volume $(10 \mu \mathrm{l})$ was subjected to electrophoresis in non-denaturing polyacrylamide gels $(8 \%, 0.75 \mathrm{~mm})$. The gels were run at 5 volt/cm until the xylene cyanol band was within the bottom gel inch. The gels were then fixed with $7 \%$ acetic acid (5 minutes), dried under vacuum (40 minutes, $80^{\circ} \mathrm{C}$ ), and put inside a developing cassette containing one intensifying screen and preflashed films (Kodak XAR; Kodak, Rochester, New York) facing the intensifying screen (16 to 48 hours, $-70^{\circ} \mathrm{C}$ ). The autoradiograms were developed using an automated processor Kodak-Omat 100 (Kodak).

Interpretation and inclusion criteria in each sample were as reported (Diaz-Cano et al, in press; Mutter and

Table 3. Primer Sequences and PCR Cycling Conditions for the Amplification of Polymorphic DNA Regions

\begin{tabular}{|c|c|c|}
\hline Primers & Primer sequences & Tandem repeat/PCR product \\
\hline$A R-a^{*}$ & 5'-CCG AGG AGC TTT CCA GAA TC-3' & CAG repeat/215-300 bp \\
\hline$A R-b^{*}$ & 5'-TAC GAT GGG CTT GGG GAG AA-3' & \\
\hline TP53(1)-ał & 5'-AGG GAT ACT ATT CAG CCC-3' & CA repeat/103-135 bp \\
\hline TP53(1)-bł & 5'-ACT GCC ACT CCT TGC CCC ATT C-3' & \\
\hline TP53(2)-ał & 5'-GAA TCC GGG AGG AGG TTG-3' & AAAAT repeat/140-175 bp \\
\hline TP53(2)-b & 5'-AAC AGC TCC TTT AAT GGC AG-3' & \\
\hline RB1-af & 5'-CTC CTC CCC TAC TTA CTT GT-3' & CTTT(T) repeat/266-306 bp \\
\hline RB1-b‡ & 5'-AAT TAA CAA GGT GTG GTG GTA CAC G-3' & \\
\hline WT1-ał & 5'-AAT GAG ACT TAC TGG GTG AGG-3' & CA repeat/ $\sim 144 \mathrm{bp}$ \\
\hline WT1-b‡ & 5'-TTA CAC AGT AAT TTC AAG CAA CGG-3' & \\
\hline NF1-af & 5'-CAG AGC AAG ACC CTG TCT-3' & CA repeat/171-187 bp \\
\hline NF1-b‡ & 5'-CTC CTA ACA TTT ATT AAC CTT A-3' & \\
\hline
\end{tabular}

All reactions were run in duplicate using $1.5 \mathrm{mM}$ of $\mathrm{MgCl}_{2}$ and $1 \mu$ l of template. A long denaturation (4 minutes) was used in the first 3 cycles for each set of primers.

* The HUMARA tests were run using $0.3 \mu \mathrm{M}$ of each primer and $200 \mu \mathrm{M}$ of each dNTP (including 7-deaza-dGTP instead of dGTP) (Boehringer-Mannheim, Indianapolis, Indiana). The amplicon was internally labeled with $\left.0.3 \mu \mathrm{Ci} \alpha{ }^{32} \mathrm{P}\right]-\mathrm{dTTP}(800 \mathrm{Ci} / \mathrm{mmol}, 10 \mathrm{mCi} / \mathrm{ml}$ ) (New England Nucleotide, Boston, Massachusetts). A "hot start" protocol was also used, completing 28 cycles with an annealing temperature of $55^{\circ} \mathrm{C}$.

$\ddagger$ The polymorphic regions of TSG were amplified using $0.25 \mu \mathrm{M}$ of each primer, $50 \mu \mathrm{M}$ of each dNTP (Boehringer-Mannheim), and internally labeled with 0.3 $\left.\mu \mathrm{Ci} \alpha{ }^{32} \mathrm{P}\right]-\mathrm{dCTP}\left(3000 \mathrm{Ci} / \mathrm{mmol}, 10 \mathrm{mCi} / \mathrm{ml}\right.$ ) (New England Nucleotide). The annealing temperature was $55^{\circ} \mathrm{C}$ for all primer sets (except for $\mathrm{NF} 1$, it was $52^{\circ} \mathrm{C}$ ), and the number of cycles was experimentally optimized to 26 . 
Boynton, 1995b). Only informative cases (two different alleles in undigested and digested control samples) were included in the final analysis (Diaz-Cano et al, in press; Mutter and Boynton, 1995b; Mutter et al, 1995) and lanes were normalized in relation to the corresponding undigested sample and controls. Allelic imbalance was densitometrically evaluated (EC model 910 optical densitometer; EC Apparatus, St Petersburg, Florida), considering evidence of monoclonality allele ratios $\geq 4: 1$ in the normalized digested lanes. The presence of additional allele bands in the tumor samples was considered positive evidence of microsatellite instability if not present in the corresponding control.

\section{LOH/SNP analyses of Tumor Suppressor Genes}

DNA was extracted from two $20-\mu \mathrm{m}$ unstained paraffin sections per tumor compartment and control samples, including at least 100 cells (approximately $0.4 \mathrm{~mm}^{2}$ ) per sample. Appropriate controls were included for each test (histologically normal urothelium, stroma from the lamina propria, and smooth muscle).

DNA was extracted using a modified phenolchloroform protocol (Diaz-Cano and Brady, 1997). DNA was precipitated with ice-cold absolute ethanol in the presence of $0.3 \mathrm{M}$ sodium acetate $\mathrm{pH} 5.2$ and resuspended in $10 \mu \mathrm{l}$ of PCR buffer $(10 \mathrm{~mm}$ Tris- $\mathrm{HCl}$ $\mathrm{pH} 8.4,50 \mathrm{~mm} \mathrm{KCl}, 1.5 \mathrm{~mm} \mathrm{MgCl}_{2}$, and $100 \mu \mathrm{g} / \mathrm{ml}$ BSA). DNA was then used for PCR amplification of polymorphic DNA regions of TSG (TP53, RB, WT1, and NF1), using the primers and conditions shown in Table 3 (Cawkwell et al, 1993, 1994). The tests were run in duplicate in a Perkin-Elmer thermal cycler model 480 (Perkin-Elmer).

The whole PCR volume $(10 \mu \mathrm{l})$ was subjected to electrophoresis in $8 \%$ denaturing gradient polyacrylamide gels $(0.75 \mathrm{~mm}, 20 \%$ to $80 \%$ denaturing conditions from top to bottom). The gels were run at 5 volt/cm until the xylene cyanol band was within the bottom gel inch. The gels were then fixed with $7 \%$ acetic acid (5 minutes), dried under vacuum (40 minutes, $80^{\circ} \mathrm{C}$ ), and put inside a developing cassette containing one intensifying screen and preflashed films (Kodak XAR) facing the intensifying screen (16 to 48 hours, $-70^{\circ} \mathrm{C}$ ). The autoradiograms were developed using an automated processor Kodak-Omat 100.

Interpretation and inclusion criteria in each sample were according to Diaz-Cano et al, (in press) and Mutter and Boynton (1995b). Only informative cases (two different alleles in control samples) were included in the final analysis (Diaz-Cano et al, in press; Mutter and Boynton, 1995b; Mutter et al, 1995). Allelic imbalance was densitometrically evaluated (EC model 910 optical densitometer; EC Apparatus). Only allele ratios $\geq 4: 1$ in any TSG were considered evidence of loss of heterozygosity ( $\mathrm{LOH})$; otherwise retention of heterozygosity $(\mathrm{ROH})$ was assigned. Additional allele bands in the tumor samples were considered positive evidence of single nucleotide polymorphism (SNP) in denaturing gradient gels if they were not present in the corresponding control.

\section{Immunohistochemical Expression of p53, pRB, and p21 WAF1}

The sections were mounted on positively charged microscope slides (Superfrost Plus; Fisher Scientific, Fair Lawn, New Jersey) and baked at $60^{\circ} \mathrm{C}$ for 2 hours. The slides were routinely dewaxed and rehydrated. The endogenous peroxidase activity was then quenched with $0.5 \% \mathrm{H}_{2} \mathrm{O}_{2}$ in methanol, 10 minutes). $A$ microwave antigen retrieval method (20 minutes in 10 $\mathrm{mm}$ citrate buffer, $\mathrm{pH} 6.0$, at 600 watts) was used, followed by incubation with polyclonal horse serum (20 minutes, 1:100 dilution; Dako, Glostrup, Denmark) and with monoclonal primary antibodies (overnight, $4^{\circ} \mathrm{C}$ ), at $2 \mu \mathrm{g} / \mathrm{ml}$ for $\mathrm{p} 53$ and $\mathrm{p} 21^{\mathrm{WAF} 1}$ and $5 \mu \mathrm{g} / \mathrm{ml}$ for pRB1 (Calbiochem, Cambridge, Massachusetts). Then sections were serially incubated with biotinylated antimouse antibody (30 minutes, 1:200 dilution; Dako), and peroxidase-labeled avidin-biotin complex (60 minutes, 1:100 dilution; Dako). All incubations were performed in moist chamber at room temperature unless otherwise specified. The reaction was developed under microscopic control, using 3,3'diaminobenzidine tetrahydrochloride with $0.3 \% \mathrm{H}_{2} \mathrm{O}_{2}$ as chromogen (Sigma Chemical, St. Louis, Missouri), and the sections counterstained with hematoxylin. Both positive (reactive lymph node) and negative (omitting the primary antibody) controls were simultaneously run.

\section{Quantification of Positive Nuclei}

The threshold of positivity was experimentally established at the positive control in each staining batch. Only those nuclei with staining features similar to those of their corresponding positive control were considered positive for a given marker. Reactivity for each marker was assessed and scored by three independent observers (SDC, AB, and JR).

At least 50 high-power fields (HPF), or the complete lesion if smaller (50 HPF $=7.6 \mathrm{~mm}^{2}$ ), were screened in each compartment; the screening began in the most cellular area. Both the number of positive nuclei per HPF and the number of neoplastic cells intercepted by the microscope field diameter were registered. The last score was used to estimate the number of neoplastic cells per HPF using the formula $N=(n \pi / 4)^{2}$, where $\mathrm{N}$ is the number of estimated cells per HPF and $\mathrm{n}$ the number of cells intercepted by the microscope field diameter (Diaz-Cano et al, 1996; Simpson et al, 1992). The number of positive nuclei was always expressed per HPF and per 1,000 proliferating cells. Both the average and the standard deviation (SD) values were calculated as representative scores per compartment and patient.

\section{Statistical Analysis}

Analysis of variance (ANOVA) and Student $t$ tests were applied to assess the differences, by tumor compart- 
ment, of average and SD values of every quantitative variable. Differences were considered statistically significant if $p<0.05$.

\section{References}

Aaltonen V, Bostrom PJ, Soderstrom KO, Hirvonen O, Tuukkanen J, Nurmi M, Laato M, and Peltonen J (1999). Urinary bladder transitional cell carcinogenesis is associated with down-regulation of NF1 tumor suppressor gene in vivo and in vitro. Am J Pathol 154:755-765.

Allen RC, Zoghbi HY, Moseley AB, Rosenblatt HM, and Belmont JW (1992). Methylation of Hpall and Hhal sites near the polymorphic CAG repeat in the human androgenreceptor gene correlates with $X$ chromosome inactivation. Am J Hum Genet 51:1229-1239.

Blanes A, Rubio J, Martinez A, Matilla A, Diaz-Cano SJ, and Wolfe HJ (1999). Kinetic profile by topographic compartments in muscle-invasive transitional cell carcinoma of the urinary bladder. Lab Invest 79:90A.

Brown JL, Russell PJ, Philips J, Wotherspoon J, and Raghavan D (1990). Clonal analysis of a bladder cancer cell line: an experimental model of tumour heterogeneity. $\mathrm{Br} \mathrm{J}$ Cancer 61:369-376.

Cawkwell L, Bell SM, Lewis FA, Dixon MF, Taylor GR, and Quirke P (1993). Rapid detection of allele loss in colorectal tumours using microsatellites and fluorescent DNA technology. Br J Cancer 67:1262-1267.

Cawkwell L, Lewis FA, and Quirke P (1994). Frequency of allele loss of DCC, p53, RBI, WT1, NF1, NM23 and APC/MCC in colorectal cancer assayed by fluorescent multiplex polymerase chain reaction. $\mathrm{Br} \mathrm{J}$ Cancer 70:813-818.

Chen LC, Kurisu W, Ljung BM, Goldman ES, Moore DI, and Smith HS (1992). Heterogeneity for allelic loss in human breast cancer. J Natl Cancer Inst 84:506-510.

Chern HD, Becich MJ, Persad RA, Romkes M, Smith P, Collins C, Li YH, and Branch RA (1996). Clonal analysis of human recurrent superficial bladder cancer by immunohistochemistry of P53 and retinoblastoma proteins. J Urol 156: 1846-1849.

Deng G, Lu Y, Zlotnikov G, Thor AD, and Smith HS (1996). Loss of heterozygosity in normal tissue adjacent to breast carcinomas. Science 274:2057-2059.

Diaz-Cano SJ (1998). Clonality studies in the analysis of adrenal medullary proliferations: Application principles and limitations. Endocr Pathol 9:301-316.

Diaz-Cano SJ, Blanes A, and Wolfe HJ (In press, 2000). PCR-based techniques for clonality analysis of neoplastic progression. Bases for its appropriate application in paraffinembedded tissues. Diagn Mol Pathol.

Diaz-Cano SJ and Brady SP (1997). DNA extraction from formalin-fixed, paraffin-embedded tissues: protein digestion as a limiting step for retrieval of high-quality DNA. Diagn Mol Pathol 6:342-346.

Diaz-Cano SJ, Leon MM, de Miguel M, Galera Davidson H, and Wolfe HJ (1996). Mitotic index quantification: Different approaches and their value in adrenocortical proliferative lesions (Abstract). Lab Invest 74:170A.
Diaz-Cano SJ and Wolfe HJ (1997). Clonality in Kaposi's sarcoma [letter; comment]. N Engl J Med 337:571-572.

Fadl-Elmula I, Bonaldi L, Gorunova L, Mandahl N, Elfving P, and Heim S (1998). Cytogenetic heterogeneity in a second primary radiation-induced bladder carcinoma: ten karyotypically unrelated clones. Cancer Genet Cytogenet 105:134137.

Furth ME, Aldrich TH, and Cordon-Cardo C (1987). Expression of ras proto-oncogene proteins in normal human tissues. Oncogene 1:47-58.

Hermann GG, Horn T, and Steven K (1998). The influence of the level of lamina propria invasion and the prevalence of p53 nuclear accumulation on survival in stage T1 transitional cell bladder cancer. J Urol 159:91-94.

Horowitz JM, Park SH, Bogenmann E, Cheng JC, Yandell DW, Kaye FJ, Minna JD, Dryja TP, and Weinberg RA (1990). Frequent inactivation of the retinoblastoma anti-oncogene is restricted to a subset of human tumor cells. Proc Natl Acad Sci USA 87:2775-2779.

Kageyama Y, Yamamura Y, Oshima H, and Ikawa $Y$ (1995). Infrequent mutations of the WT1 gene in primary cancers of the adult urinary tract. Jpn J Clin Oncol 25:173-178.

Knudson AG (1995). Mutation and cancer: A personal odyssey. Adv Cancer Res 67:1-23.

Mutter GL and Boynton KA (1995a). PCR bias in amplification of androgen receptor alleles, a trinucleotide repeat marker used in clonality studies. Nucleic Acids Res 23:1411-1418.

Mutter GL and Boynton KA (1995b). X chromosome inactivation in the normal female genital tract: implications for identification of neoplasia. Cancer Res 55:5080-5084.

Mutter GL, Chaponot ML, and Fletcher JA (1995). A polymerase chain reaction assay for non-random $X$ chromosome inactivation identifies monoclonal endometrial cancers and precancers. Am J Pathol 146:501-508.

Nordenson I, Ljungberg B, and Roos G (1988). Chromosomes in renal carcinoma with reference to intratumor heterogeneity. Cancer Genet Cytogenet 32:35-41.

Nowell PC (1976). The clonal evolution of tumor cell populations. Science 194:23-28.

Ro JY, Ayala AG, and el-Naggar A (1987). Muscularis mucosa of urinary bladder. Importance for staging and treatment. Am J Surg Pathol 11:668-673.

Sager R (1989). Tumor suppressor genes: The puzzle and the promise. Science 246:1406-1412.

Sidransky D, Frost P, Von Eschenbach A, Oyasu R, Preisinger AC, and Vogelstein B (1992). Clonal origin bladder cancer. N Engl J Med 326:737-740.

Sidransky D, Von Eschenbach A, Tsai YC, Jones P, Summerhayes I, Marshall F, Paul M, Green P, Hamilton SR, Frost P, and Vogelstein $B$ (1991). Identification of p53 gene mutations in bladder cancers and urine samples. Science 252:706-709.

Simpson JF, Dutt PL, and Page DL (1992). Expression of mitoses per thousand cells and cell density in breast carcinomas: a proposal. Hum Pathol 23:608-611.

Smits G, Schaafsma E, Kiemeney L, Caris C, Debruyne F, and Witjes JA (1998). Microstaging of pT1 transitional cell carcinoma of the bladder: identification of subgroups with distinct risks of progression. Urology 52:1009-1013. 
Sternlicht M, Mirell C, Safarians S, and Barsky SH (1994). A novel strategy for the investigation of clonality in precancerous disease states and early stages of tumor progression. Biochem Biophys Res Commun 199:511-518.

Uchida T, Wada C, Ishida H, Egawa S, Ao T, Yokoyama E, and Koshiba K (1995). Infrequent involvement of mutations on neurofibromatosis type $1, \mathrm{H}$-ras, $\mathrm{K}$-ras and $\mathrm{N}$-ras in urothelial tumors. Urol Int 55:63-67.

Voorter C, Joos S, Bringuier PP, Vallinga M, Poddighe P, Schalken J, du Manoir S, Ramaekers F, Lichter P, and Hopman A (1995). Detection of chromosomal imbalances in transitional cell carcinoma of the bladder by comparative genomic hybridization. Am J Pathol 146:1341-1354.
Wolman SR and Heppner GH (1992). Genetic heterogeneity in breast cancer. J Natl Cancer Inst 84:469-470.

Younes M, Sussman J, and True LD (1990). The usefulness of the level of the muscularis mucosae in the staging of invasive transitional cell carcinoma of the urinary bladder. Cancer 66:543-548. 